\title{
O DEBATE PARLAMENTAR EM TORNO DA LEI CONTRA A TORTURA NO BRASIL
}

\author{
Pedro Benetti \\ Fernando Sallaii \\ Marcos César Alvareziii
}

\section{RESUMO}

O presente artigo se dedica ao levantamento e análise das propostas legislativas em torno do tema da tortura, ao longo das últimas décadas no Brasil. Para entender de que maneira os políticos brasileiros abordaram este problema em sua atividade parlamentar, nos dedicamos a pesquisar quais foram as iniciativas apresentadas e, em casos específicos, quais foram os conteúdos debatidos no processo de deliberação acerca das mesmas. Observamos que, a despeito do número reduzido de matérias que efetivamente se converteram em norma jurídica, houve elevada produção de proposições acerca do tema, o que justifica um esforço para compreender quem são seus autores, quais os pontos específicos que abordam e como nos ajudam a traçar um panorama de como o problema é percebido e debatido no campo da representação institucional.

PALAVRAS-CHAVE: tortura; sociologia da punição; poder legislativo; leis.

' Universidade do Estado do Rio de Janeiro (UERJ), Rio de Janeiro, RJ, Brasil ORCID; ii Universidade de São Paulo (USP), São Paulo, SP, Brasil ORCID; iii Universidade de São Paulo (USP), São Paulo, SP, Brasil, ORCID. 


\title{
THE PARLIAMENTARY DEBATE OVER THE LAW AGAINST TORTURE IN BRAZIL
}

\author{
Pedro Benetti \\ Fernando Salla \\ Marcos César Alvarez
}

\begin{abstract}
This article is dedicated to the survey and analysis of the legislative proposals around the theme of torture over the last decades in Brazil. In order to understand how Brazilian representatives approached this problem in their parliamentary activity, we dedicate ourselves to researching what legislative proposals were presented and, in specific cases, what were the contents discussed in the deliberation process about them. We observed that, despite the reduced number of articles that effectively became a legal norm, there was a high production of initiatives on the subject, which justifies an effort to understand who the authors are, what specific points they address and how they help us to trace an overview of how the problem is perceived and debated in the field of institutional representation.
\end{abstract}

KEYWORDS: torture; sociology of punishment; legislative power; laws. 


\section{INTRODUÇÃO}

“(...) Mas o abismo, na realidade, é imenso entre a literatura e o choque, entre os argumentos e a porrada; e o que responder à porrada, como contraargumentar à descarga senão através do grito ou da rajada de fezes? (...)

Luiz Roberto Salinas Fortes, Retrato Calado

O presente artigo analisa as propostas de alteração legislativa apresentadas na Câmara dos Deputados acerca do tema da tortura, com ênfase no percurso de aprovação da lei n. .9 .455 , de 1997, conhecida como lei contra a tortura. Ainda que poucas tenham sido as normas jurídicas criadas nessa seara ao longo das últimas décadas, observamos uma profusão de iniciativas ingressadas pelos deputados, o que justifica o esforço de sistematizá-las e de compreender de que maneira entendem e propõe soluções para o problema da tortura.

O tema da tortura é bastante complexo, tanto no que diz respeito ao combate a essa prática, quanto nas reflexões acerca de sua história e permanência. Mesmo que seja uma ação que revele os aspectos mais sórdidos da condição humana e coloque em xeque qualquer concepção de civilização, a tortura não foi totalmente erradicada na maior parte dos países, a despeito do crescente consenso legal e moral de que se trata de algo bárbaro e que fere a dignidade humana. Divergências em termos da definição do que seria tal prática igualmente permanecem, embora seja possível circunscrever o âmbito do problema às ações que envolvem o Estado e suas instituições e operadores (Sussman, 2005; Alvarez, 2008; Mendiola, 2020).

Também no Brasil, a tortura é prática que se encontra de modo persistente na história do país, seja em decorrência de perseguição política, como no Estado Novo ou na ditadura militar (1964-1983), seja como instrumento de gestão da 
criminalidade comum (Salla \& Alvarez, 2006). Mas nem sempre essa presença se refletiu no tratamento da questão como um problema político. Em outras palavras, embora tenha existido ao longo de toda nossa história, a tortura não esteve sempre presente nos discursos públicos, nos diplomas legais e, de maneira geral, no horizonte das instituições brasileiras. A transição da última ditadura militar para o atual regime democrático contribuiu para lançar luz sobre o tema, ao aumentar a demanda de atores sociais diversos pela construção de normas jurídicas e políticas públicas capazes de lidar com o tema.

A reflexão e a pesquisa nas Ciências Sociais têm buscado avançar na compreensão do tema no Brasil, em múltiplas dimensões. A publicação do livro "Brasil: Nunca Mais" (1985) foi um marco, tanto em termos políticos, quanto em termos de divulgação de material para a pesquisa acerca das práticas de tortura durante a ditadura civil-militar implantada a partir de 1964. Martha Huggins, por sua vez, entrevistou os "operários da violência", policiais que praticaram torturas no período 1964-1985, ao buscar compreender as representações e justificativas desses atores em relação às atrocidades cometidas (Huggins, 2006). Os efeitos psíquicos e subjetivos das torturas perpetradas durante a ditadura civil-militar (Ocariz, 2015); a importância de quebrar o silêncio acerca da violência e dos torturadores em termos de memória e de história (Reis, 2010; Fortes, 2012); as práticas ainda atuais de tortura no inquérito policial e na construção da verdade na justiça criminal (Jesus, 2010; Vargas, 2012); a tortura e seu combate dentro e fora das prisões (Godoi, 2019); o processo político da criação da lei contra a tortura no Brasil (Possas, 2016) são alguns das questões que têm sido exploradas.

As últimas décadas assistiram igualmente ao progressivo aumento de iniciativas relacionadas ao combate à tortura em diferentes níveis do poder público. Para o presente texto, concentramos nossos esforços em compreender de que maneira esta questão apareceu nos registros da Câmara dos Deputados, a casa legislativa que, em nível federal, registra maior número de menções à tortura em 
seu acervo.' Pretendemos, por meio da análise das proposições legislativas relacionadas a este tema, compreender os eixos principais do debate travado pelos representantes, com menor preocupação acerca do destino das propostas. Nesta reflexão, não nos interessam imediatamente os efeitos concretos destas propostas no ordenamento jurídico, mas sim utilizá-las como um indicador do tipo de discussão que permeia a questão da tortura na atualidade. Para cumprir este objetivo, dividiremos o presente trabalho em duas etapas, sendo a primeira uma breve contextualização da maneira como a tortura passou a compor o debate público brasileiro, a partir dos anos 1980, com seus desdobramentos jurídicos, na forma da lei n. 9.455/97; e a segunda, mais detalhada, oferecendo uma visão geral da atividade dos deputados federais no que se refere ao tema, subdividida de acordo com os diferentes momentos da atividade legislativa levantada.

\section{BREVE HISTÓRICO: DA TRANSIÇÃO À LEI 9.455/97}

A volta do país à normalidade democrática, a partir da década de 1980, criou um ambiente político favorável ao reconhecimento, pelo governo brasileiro, dos instrumentos internacionais de prevenção e combate à tortura (sobretudo a Convenção das Nações Unidas contra a Tortura e outros Tratamentos ou Penas Cruéis, Desumanos ou Degradantes e a Convenção Interamericana para Prevenir e Punir a Tortura), o que ocorreu em 1989. No curso dos anos 1980, o tema da tortura ocupara, talvez de maneira inédita, posição de centralidade no debate público brasileiro. As críticas de uma ampla frente de atores sociais contrários ao regime autoritário, a partir do fim da década de 1970, se condensavam na denúncia ao uso

\footnotetext{
1 O Senado Federal registra 110 proposições legislativas com o termo tortura, ao passo que a Câmara dos Deputados supera os 500 resultados. Por essa razão decidimos concentrar os esforços na análise do material produzido na Câmara dos Deputados, sem deixar de reconhecer a importância de desdobrar a presente pesquisa numa análise complementar da outra casa legislativa. https://www6g.senado.leg.br/busca/?q=tortura\&colecao=Projetos\%20e\%20Mat\%C3\%A9rias\%20\%20Proposi\%C3\%A7\%C3\%B5es
} 
recorrente deste expediente por parte das forças de segurança do Estado. A Comissão de Justiça e Paz da Arquidiocese de São Paulo e o Grupo Tortura Nunca Mais são exemplares da mobilização em torno do tema, que não esteve limitado às discussões no âmbito da sociedade civil. O impacto de trabalhos como o relatório Brasil: Nunca Mais, lançado quatro meses após a posse do primeiro presidente civil, foi determinante para que as preocupações acerca da prática de tortura fossem manifestadas também por atores importantes do sistema político. Nesse sentido, iniciativas como a criação da Comissão Teotônio Vilela (CTV), formada por parlamentares eleitos e membros da sociedade civil, foram fundamentais na tradução das denúncias para uma linguagem de recomendações específicas, que deveriam produzir transformações nos marcos legais, bem como na formulação e implementação de políticas públicas.

Estes debates se refletem de maneira direta na Constituição de 1988, que em seu texto original registra a palavra tortura apenas duas vezes, ambas no artigo $5^{\circ}$. No terceiro inciso, a Carta afirma que "ninguém será submetido a tortura nem a tratamento desumano ou degradante;" e no quadragésimo terceiro diz que "a lei considerará crimes inafiançáveis e insuscetíveis de graça ou anistia a prática da tortura, o tráfico ilícito de entorpecentes e drogas afins, o terrorismo e os definidos como crimes hediondos, por eles respondendo os mandantes, os executores e os que, podendo evitá-los, se omitirem". Há menção ainda à abolição de penas cruéis, trabalhos forçados, pena de morte e prisão perpétua. Estas passagens representam inflexões em relação ao texto constitucional outorgado pelo regime militar anterior, em 1967, no qual o termo tortura está completamente ausente. Ainda assim, como era esperado, a constituição de 1988 oferece apenas as linhas fundamentais que deverão orientar a produção de legislação subsequente, de maneira a avançar tanto o arcabouço jurídico quanto a estrutura de capacidades institucionais aptos ao enfrentamento ativo do problema da tortura.

A década de 1990 apresenta um cenário ambíguo, no qual resta aos legisladores enorme trabalho de regulamentação dos preceitos constitucionais, mas o ambiente político de urgência em relação a determinados temas se dissipa 
progressivamente, passando a dividir espaço com novas prioridades que surgem a cada dia. Nesse contexto de transição, a tramitação dos projetos, antes da aprovação da lei em 1997, revelou uma tensão política que acabou por retirar a tortura, não obstante o esforço de alguns deputados em sentido contrário, como elemento chave nos debates em torno da lei de segurança nacional, crimes contra - Estado democrático e a humanidade. O projeto de lei, de iniciativa do poder executivo, que se tornaria norma em 1997, foi expurgado destas tramas políticas de maior abrangência, elas mesmas cada vez menos presentes no debate público local.

O trâmite de aprovação do projeto n. ${ }^{\circ} 4.716 / 94$, que se tornaria lei n. 9.455, foi apressado pelos acontecimentos de violência policial ocorridos na Favela Naval, em Diadema, no estado de São Paulo, em março de 1997. Até o surgimento da lei, os casos de tortura eram punidos como lesão corporal ou constrangimento ilegal. A lei n. ${ }^{\circ} 9.455$, no seu artigo $1^{\circ}$, determinou que é crime de tortura:

I. Constranger alguém com emprego de violência ou grave ameaça, causando-Ihe sofrimento físico ou mental:

a) com o fim de obter informação, declaração ou confissão da vítima ou de terceira pessoa;

b) para provocar ação ou omissão de natureza criminosa;

c) em razão de discriminação racial ou religiosa.

II. Submeter alguém, sob sua guarda, poder ou autoridade, com emprego de violência ou grave ameaça, a intenso sofrimento físico ou mental, como forma de aplicar castigo pessoal ou medida de caráter preventivo.

Uma breve comparação entre o que dispôs a lei brasileira e o que dispõe a Convenção da ONU contra a Tortura apresenta alguns aspectos a serem destacados. O primeiro deles é que a lei brasileira, na letra $c$ do inciso I do artigo $1^{\circ}$, 
restringiu o elemento discriminação aos aspectos racial e religioso. Já na Convenção a discriminação é de qualquer natureza (art. 1o.). Ficaram de fora desse enquadramento, por exemplo, entre outras, a discriminação por orientação sexual.

O segundo aspecto, e mais importante, é quanto ao agente que pratica a tortura. A lei brasileira não restringiu esse crime ao agente público ou a pessoa em exercício de funções públicas, enquanto a Convenção ao definir a tortura, de forma explícita, faz essa restrição, no seu artigo $1^{\circ}$ :

1. Para os fins da presente Convenção, o termo "tortura" designa qualquer ato pelo qual dores ou sofrimentos agudos, físicos ou mentais, são infligidos intencionalmente a uma pessoa a fim de obter, dela ou de uma terceira pessoa, informações ou confissões; de castigá-la por ato que ela ou uma terceira pessoa tenha cometido ou seja suspeita de ter cometido; de intimidar ou coagir esta pessoa ou outras pessoas; ou por qualquer motivo baseado em discriminação de qualquer natureza; quando tais dores ou sofrimentos são infligidos por um funcionário público ou outra pessoa no exercício de funções públicas, ou por sua instigação, ou com o seu consentimento ou aquiescência. Não se considerará como tortura as dores ou sofrimentos que sejam conseqüência unicamente de sanções legítimas, ou que sejam inerentes a tais sanções ou delas decorram. (grifo nosso).

Uma vez aprovada a lei, várias foram as polêmicas que se desdobraram e que se refletiram em parte no material (projetos de lei) que nos propusemos a analisar aqui. Dentre elas: o alinhamento mais preciso aos instrumentos internacionais dos quais o país é signatário; o agravamento das penas estipuladas na lei; ajustes que permitissem tipificar a violência doméstica e contra a mulher como práticas de tortura; a questão da responsabilização dos agentes públicos.

De todo modo, mesmo depois de aprovada a lei, estudos têm mostrado que a prática da tortura continua presente no cotidiano das ações policiais, nos ambientes de confinamento, seja para adultos ou para adolescentes (Pastoral 
Carcerária, 2016; Pastoral Carcerária Nacional, 2018; Salla, Jesus \& Jesus, 2016; Gomes, 2017; Calderoni \& Jesus, 2015; NEV-Núcleo de Estudos da Violência, 2012). E, ainda, como faculta a nossa lei, de certo modo à revelia dos propósitos fixados nos instrumentos internacionais, vem sendo ela aplicada com maior frequência nos casos de violência interpessoal do que como prática promovida por agentes públicos (Jesus, 2010). Por isso, cabe investigar de que maneira o debate político em torno do tema da tortura segue produzindo registros e mobilizando atores em torno de diferentes posições, ao confirmar a percepção de que os marcos legais até aqui produzidos não resultaram em pacificação das disputas acerca da delimitação do que é tortura, bem como da maneira como este problema deve ser enfrentado. Nos seus estudos, Possas (2015 e 2016), com base na teoria da Racionalidade Penal Moderna de Álvaro Pires (2004), analisou o debate político acerca da produção da lei sobre a tortura e os diversos paradoxos do posicionamento tanto de militantes de direitos humanos como de parlamentares em relação às percepções da tortura como crime contra a humanidade ou como um crime comum. Possas apontou também as dificuldades de delimitação jurídica dos chamados crimes contra a humanidade, mesmo nos documentos internacionais de proteção aos direitos humanos, mas sua presença constante nos debates parlamentares em torno da tortura. Sua reflexão compõe uma moldura ampla na qual se inserem os processos políticos e parlamentares que aqui se busca analisar.

Antes de avançar sobre a sequência das propostas de alteração da lei n. ${ }^{\circ}$ 9.455/97, nos parece fundamental recuperar o histórico de iniciativas legislativas concernentes ao tema da tortura até a promulgação da lei, de forma que estabeleçamos também a compreensão do contexto no qual tais debates têm sido produzidos pelos representantes brasileiros.

\section{O PERCURSO DA PESQUISA}


Boa parte das fontes acerca do tema da tortura na legislação brasileira concentra seu olhar sobre a lei n. ${ }^{\circ}$ 9.455/97, considerada um marco no enfrentamento do problema. Isso não significa, no entanto, que as discussões neste tópico tenham se encerrado em 1997. Tomando a Câmara dos Deputados como espaço institucional a ser pesquisado, observamos significativa atividade dos representantes no que diz respeito à tortura. Realizamos uma pesquisa no acervo da casa utilizando o termo "tortura", que apresentou 1949 resultados. Como este universo é composto de diversos tipos de documentos, como requerimentos (mais de 400), relatórios, emendas, comunicações e outros, optamos por reduzir a seleção apenas às entradas de propostas que pudessem resultar em aprovação de nova legislação, ${ }^{2}$ o que nos trouxe 516 resultados. ${ }^{3}$ Destes, 46 propostas foram registradas entre 1968 e 1996, antes, portanto, da aprovação da legislação mencionada acima. Entre as 46, cinco foram registradas durante o regime militar (1964-1985) e outras 41 entre 1985 e 1996. As demais 470 foram apresentadas após a lei n. 9.455/97, o que revela intensa mobilização em torno do tema mesmo depois da adoção de normativa legal a seu respeito.

Apesar do vasto universo de registros sobre o tema, os mecanismos de busca permitem traçar algumas características básicas do material, antes que busquemos algum aprofundamento na investigação. A grande maioria das entradas refere-se a projetos de lei (466), instrumento legislativo que prevalece sobre as demais categorias.

\section{Tabela 1}

\footnotetext{
2 Pesquisamos, assim, os seguintes tipos de proposição: PEC - Proposta de Emenda à Constituição, PLP - Projeto de Lei Complementar, PL - Projeto de Lei, MPV - Medida Provisória, PLV - Projeto de Lei de Conversão, PDC - Projeto de Decreto Legislativo, APJ - Anteprojeto, PLC - Projeto de Lei da Câmara dos Deputados (SF), PLN - Projeto de Lei (CN), PLS - Projeto de Lei do Senado Federal.

${ }^{3}$ É importante ressaltar que os resultados de pesquisa podem mudar mesmo seguindo os parâmetros indicados, já que novas entradas são constantemente inseridas no acervo da Câmara dos Deputados.
} 
Tipo das propostas legislativas, 1968-2021

\begin{tabular}{|c|c|}
\hline Tipo & $\mathrm{n}$. \\
\hline Medida Provisória & 2 \\
\hline Projeto de DEC Legislativo & 24 \\
\hline Projeto de lei & 466 \\
\hline Projeto de lei complementar & 10 \\
\hline Projeto de lei de conversão & 1 \\
\hline Proposta de emenda à & \\
\hline Constituição & 13 \\
\hline$\overline{\text { Total }}$ & 516 \\
\hline
\end{tabular}

Fonte: Câmara dos Deputados Federal. Elaboração própria4

Também verificamos que há equilíbrio na situação das propostas, sendo aproximadamente metade delas em tramitação e a outra metade arquivada.

\section{Figura 1:}

Distribuição percentual das propostas

\footnotetext{
${ }^{4}$ Todas as figuras apresentadas no texto foram elaboradas pelos autores a partir dos resultados obtidos nos mecanismos de busca do sítio da Câmara dos Deputados.
} 


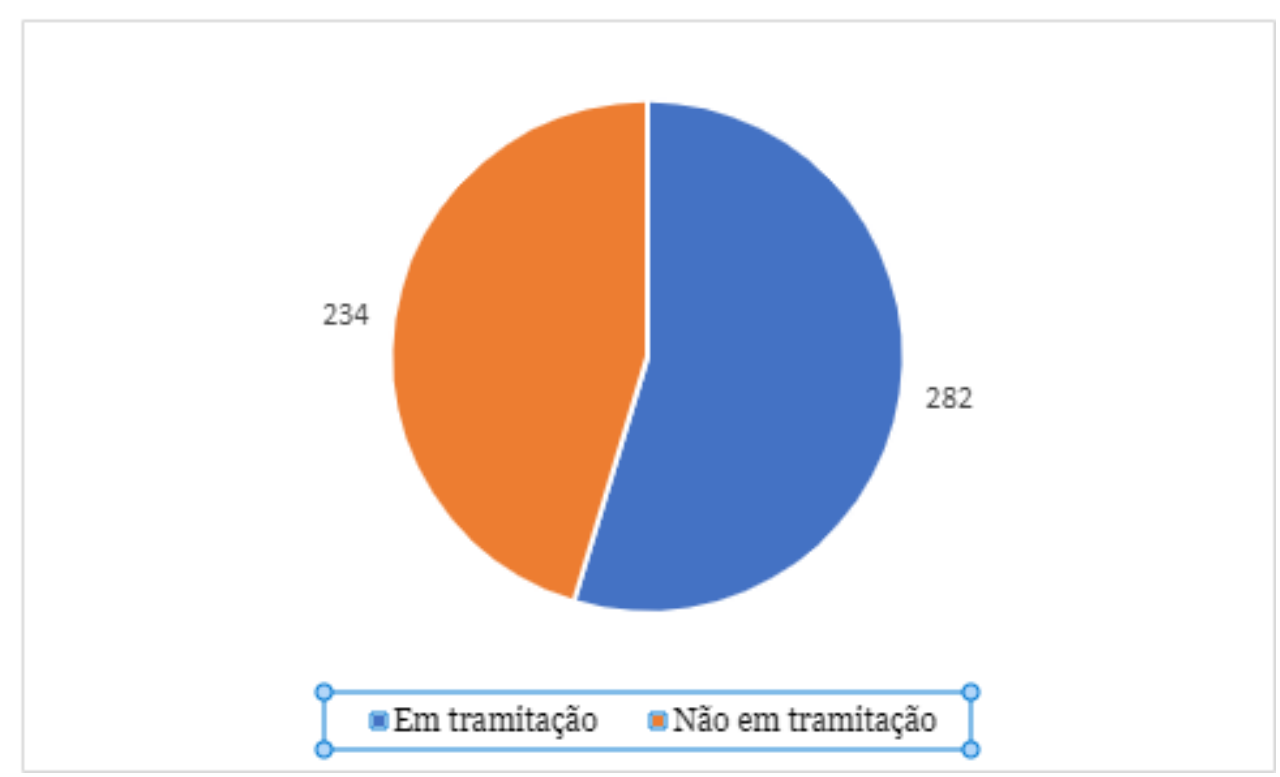

No que diz respeito aos estados de origem percebemos que há significativa distância entre o número de proposições de parlamentares de São Paulo e Rio de Janeiro em relação ao resto do país.

\section{Figura 2:}

Estados a que pertencem os autores das propostas 


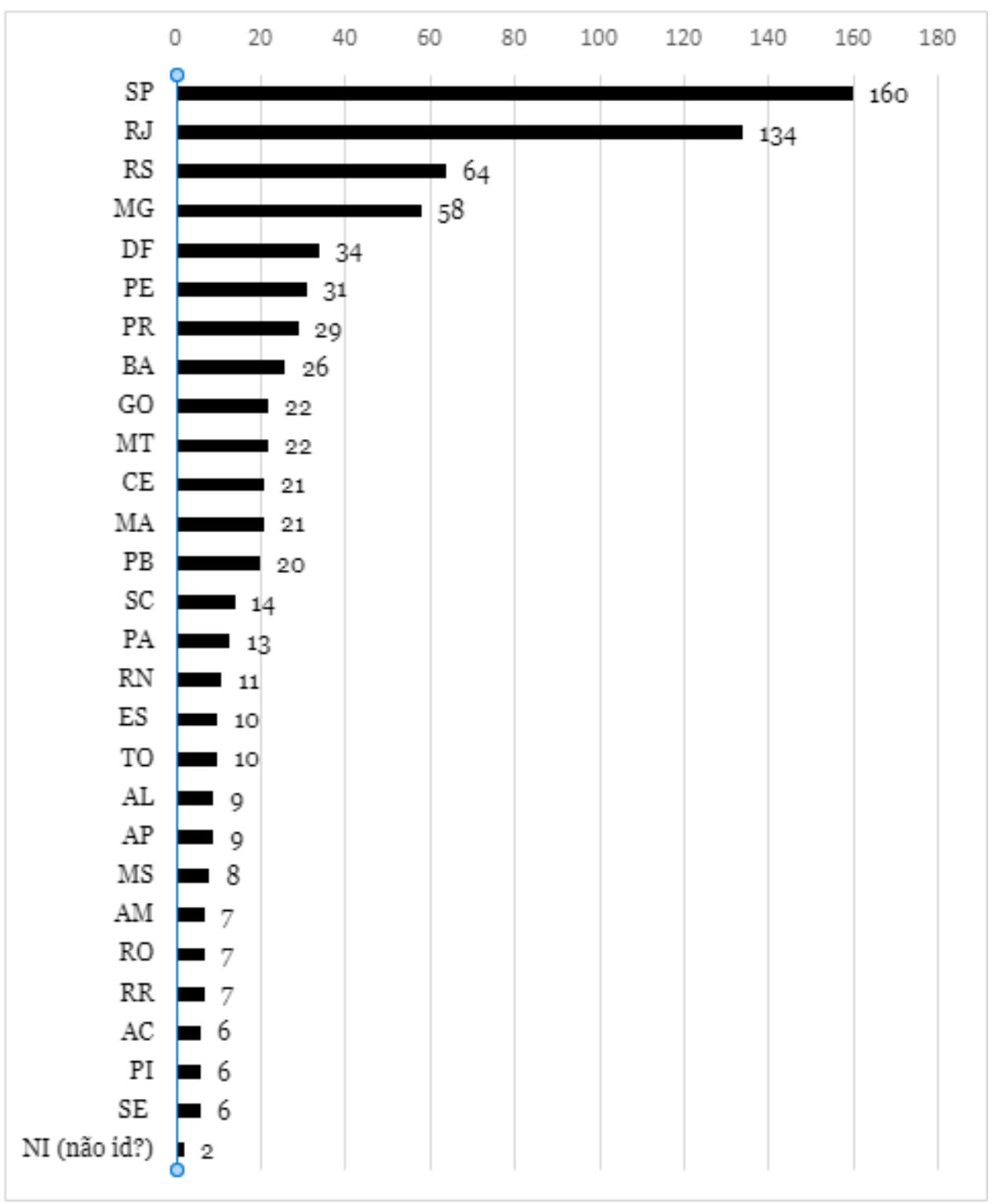

De todo modo, foi possível observar que o tamanho das bancadas parece ter relação com o número de propostas, na medida em que as unidades federativas mais populosas e, portanto, representadas em maior número de deputados, foram as responsáveis pela ampla maioria das matérias registradas.

Com relação aos partidos responsáveis pelas propostas, observamos a predominância dos partidos situados à esquerda do espectro político. ${ }^{5}$

${ }^{5}$ Embora as definições ideológicas dos partidos políticos brasileiros sejam objeto de constante polêmica, os partidos com maior número de propostas legislativas acerca do tema da tortura constam como parte da esquerda em classificações com ampla circulação, como a seguinte: 


\section{Figura 3:}

Partidos a que pertencem os autores das propostas

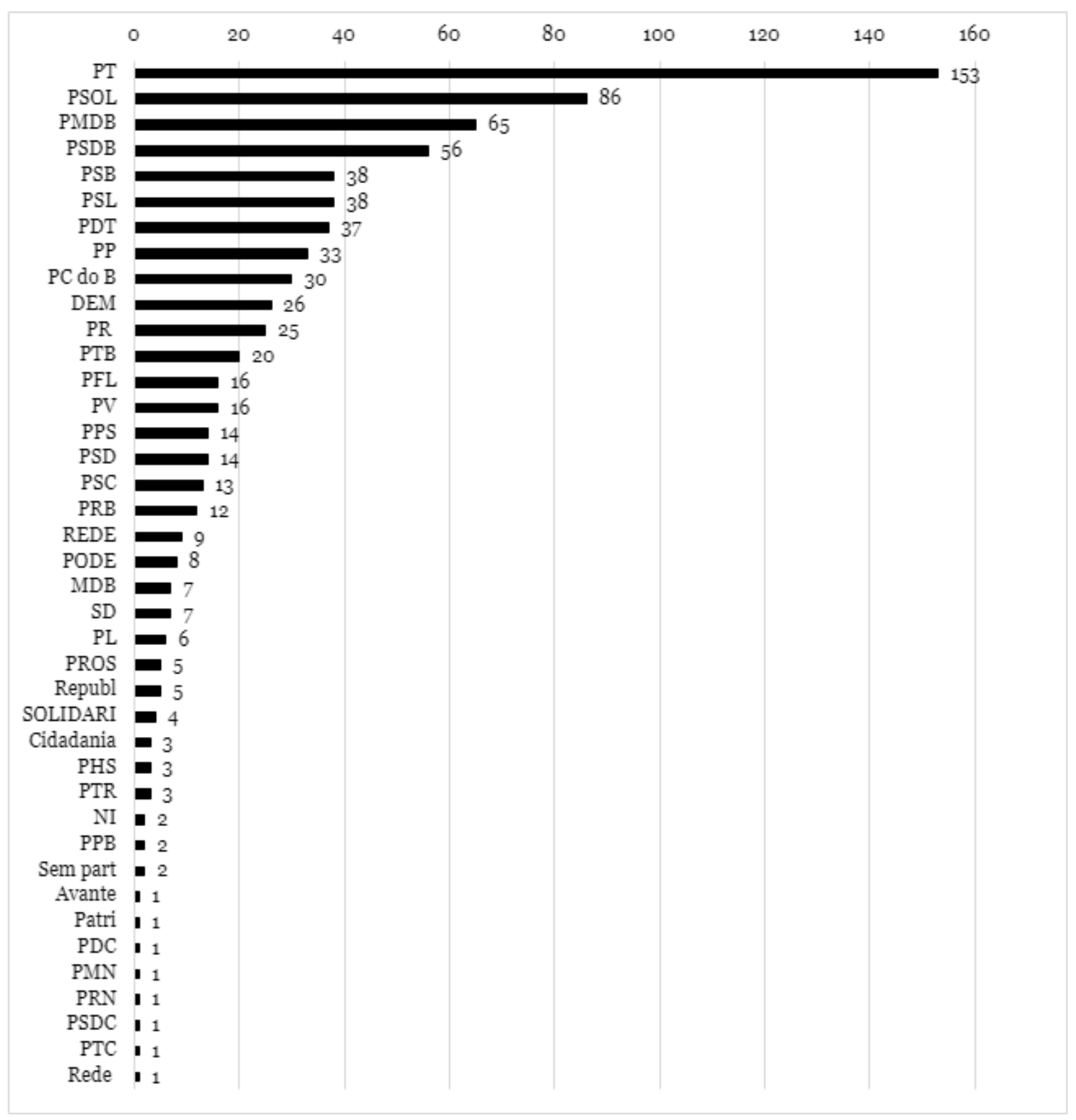

https://noticias.uol.com.br/colunas/observatorio-das-eleicoes/2020/11/24/esquerda-centro-oudireita-como-classificar-os-partidos-no-brasil.htm 
Se considerarmos PT, PSOL, PSB, PDT e PCdoB como partidos de esquerda/centro-esquerda, em definição que parece suscitar pouca polêmica, concluiremos que, das 516 entradas registradas no acervo da Câmara com o assunto tortura, 344 foram propostas por estes atores, mais de $65 \%$ das propostas. Impressiona, nesse sentido, o número de propostas apresentadas pelo PSOL, tendo em vista que o partido nunca teve bancada superior a 10 parlamentares em uma mesma legislatura. Cabe lembrar ainda que as definições ideológicas dos partidos não são fixas e como nossa pesquisa abrange um amplo arco temporal, é possível que atores hoje classificados como direita/centro-direita tenham, em algum momento, sido posicionados pelos analistas e por seus próprios parlamentares como identificados com a esquerda do espectro ideológico. Esse nos parece o caso do papel desempenhado pelos deputados do MDB, ao longo da ditadura e, em alguma medida, no período da transição, quando apresentaram a maioria das propostas relativas à tortura.

Para a sequência da discussão, propomos uma periodização das propostas em três momentos, sendo o primeiro relativo ao regime militar (1964-1985), o segundo ao período que vai do primeiro governo civil à aprovação do $\mathrm{PL}$ n. ${ }^{\circ}$ 4.716/94 na Câmara dos Deputados (1985-1996) e o último ao momento compreendido entre a aprovação deste marco legal e os dias atuais (1996-2021). Além dos três intervalos temporais, apresentaremos brevemente alguns pontos acerca da tramitação do próprio PL n. ${ }^{\circ}$ 4.716/94 na Câmara dos Deputados.

\section{PERÍODO 1968-1984}


Durante os governos militares (1964-1985), encontramos cinco propostas legislativas que se dedicam ao tema da tortura (PL n.- 1.436/68; PL n. ${ }^{\circ} 1.370 / 73 ;{ }^{7} \mathrm{PL}$ n. ${ }^{\circ} 2.710 / 80 ; 8$ PL n. ${ }^{\circ} 5.714 / 81^{9}$ e PL n. $\left.876 / 83^{10}\right)$. Estas poucas propostas guardam enorme coesão temática entre si, referindo-se sempre à preocupação dos parlamentares em eliminar a tortura do rol de instrumentos de interrogatório utilizados pelo regime autoritário. Apesar de dispersas no tempo (1968, 1973, 1980, 1981 e 1983), elas mantêm algumas características comuns, que não necessariamente são observadas nas propostas posteriores.

Em primeiro lugar, destacamos que foram todas de autoria de parlamentares da oposição, alguns deles figuras destacadas na denúncia das graves violações aos direitos humanos perpetradas pelos militares no poder. Marcello Cerqueira, por exemplo, foi exilado, preso, torturado e responsável pela defesa jurídica de diversos presos políticos. O deputado se destacou por distribuir, em 1976, carta de Aldo Arantes (PCdoB) denunciando as torturas que sofrera, o primeiro documento desta natureza a circular na grande imprensa brasileira." O deputado Lysâneas Maciel foi outro nome de destaque na defesa dos direitos humanos e na denúncia ao arbítrio militar, razão pela qual chegou a ter seu mandato cassado em 1976, o que o levou ao exílio na Suíça. ${ }^{12}$

\footnotetext{
${ }^{6} \mathrm{https} / / \mathrm{www}$. camara.leg.br/proposicoesWeb/fichadetramitacao?idProposicao=192108 de autoria do Dep. Levy Tavares (MDB/SP)

${ }^{7}$ https://www.camara.leg.br/proposicoesWeb/fichadetramitacao?idProposicao=191248 de autoria do Dep. Lysaneas Maciel (MDB/RJ)

${ }^{8} \mathrm{https} / /$ www.camara.leg.br/proposicoesWeb/fichadetramitacao?idProposicao=206023 de autoria do Dep. Marcello Cerqueira (PMDB/RJ)

${ }^{9} \mathrm{https} / /$ www.camara.leg.br/proposicoesWeb/fichadetramitacao?idProposicao=228648 de autoria do Dep. Edson Khair (PMDB/RJ)

$10 \mathrm{https} / /$ www.camara.leg.br/proposicoesWeb/fichadetramitacao?idProposicao=183818 de autoria do Dep. Marcelo Cordeiro (PMDB/BA)

$"$ Ver http://www.fgv.br/cpdoc/acervo/dicionarios/verbete-biografico/marcelo-augusto-dinizcerqueira

${ }^{12}$ Ver http://www.fgv.br/cpdoc/guia/detalhesfundo.aspx?sigla=LM
} 
Uma segunda característica em comum é que todas as propostas foram arquivadas, mesmo aquelas que chegaram a tramitar nas comissões da casa. À exceção do $\mathrm{PL}$ n. ${ }^{\circ} 1.436 / 68$, todas as matérias passaram pelo menos pela Comissão de Constituição e Justiça, com parecer e aprovação de relatório favoráveis ao seu andamento. No entanto, foram arquivadas pelas mesas diretoras da Câmara antes de votação em plenário. Apenas o $\mathrm{PL} n$. $^{\circ}$ 2.710/80 foi rejeitado pelos pares, em votação realizada em 1982. Também chama atenção que os tempos de tramitação variaram entre as cinco propostas analisadas. Enquanto a primeira e a última foram arquivadas no espaço de meses após sua proposição, as demais tramitaram em diferentes espaços da Câmara por períodos superiores a dois anos, chegando a dez anos de tramitação no caso da matéria que mais movimentos teve, a apresentada por Lysâneas Maciel em 1973.

Por fim, o terceiro e mais importante traço das propostas legislativas acerca do tema da tortura durante o período militar é a convergência de todas em abordar o tema a partir de sua inegável vinculação com o problema do exercício da autoridade por agentes públicos. Nesse sentido, ainda em 1968, o deputado Levy Tavares propôs eliminar as provas de inquérito policial obtidas sob tortura, com imediata suspensão dos processos relacionados e abertura de investigação sobre os responsáveis pelo delito penal. Cinco anos depois, o deputado Maciel propôs medida que oferecesse "Proteção judiciária imediata aos presos ou detidos". Mais adiante, Cerqueira proporia a definição de violência arbitrária, no artigo 322 do Código Penal, justificando-se da seguinte forma:

Quase que diariamente, os jornais dão notícias de toda sorte de violências praticadas contra prisioneiros indefesos. A técnica apurou o requinte dos torturadores. Jornais e revistas têm publicado, inclusive, desenhos dos aparelhos inventados pela imaginação criminosa de cidadãos investidos de autoridade, mas que utilizam os cargos e os meios que a sociedade Ihes confiou para guarda dos direitos individuais, da vida, da liberdade e da incolumidade dos cidadãos, para, numa inversão aberrante, praticar os crimes mais bestiais que, na maioria das vezes, ficam impunes. (...) 
instrumentos legais se revelaram impotentes para conter a onda de violências praticadas pela autoridade pública contra cidadãos indefesos, muitas vezes pelo simples fato de divergências políticas. ${ }^{13}$

Todos os projetos definem claramente a necessidade de proteção dos cidadãos custodiados pelo Estado ou em contato com autoridade pública no exercício de suas funções. ${ }^{14}$ Os projetos legislativos do período 1968-1983 são uníssonos na delimitação do problema a partir da necessidade de proteger os cidadãos do arbítrio exercido por indivíduos investidos de autoridade pública.

\section{PERÍODO 1985-1996}

Entre 1985 e 1996, quando a lei n. $9.455 / 97$ foi aprovada pelo plenário da Câmara dos Deputados, foram 41 proposições legislativas, que apresentaram maior diversidade entre si na comparação com as cinco propostas feitas no período do regime militar. Vale notar, por exemplo, que muitos dos projetos versam sobre a regulamentação de artigos da Constituição de 1988, razão pela qual o ano de 1989 destaca-se como período com maior número de propostas legislativas (11), muito à frente dos demais anos em termos de produção. Pelo menos 10 propostas, no período, visam regulamentar o artigo quinto da Constituição, mencionando diferentes incisos.

\footnotetext{
13 Justificativa constante no Projeto de Lei apresentado por Marcelo Cerqueira, cujo link de acesso foi disponibilizado na nota 9.

14 O deputado Edson Khair propõe introduzir "Alterações no Código Penal e no Código Penal Militar, para o fim de definir como crime de tortura a prática de maus tratos, físicos ou morais, por agente da autoridade". E o deputado Marcelo Cordeiro pretende alterar o artigo 322 do Código Penal para acrescentar a seguinte redação: "Se a violência consiste em tortura, suplício ou grave tormento físico ou psicológico à pessoa sob a autoridade, guarda, vigilância ou custódia do funcionário". As informações constam nas justificativas para apresentação dos projetos de lei, que podem ser consultados no sítio da Câmara dos Deputados usando o número do PL, conforme apresentado nas notas $7,8,9,10,11$.
} 
Nesse período já observamos ampla gama de atores políticos envolvidos na proposição de textos. O Poder Executivo, antes completamente ausente, é responsável por protocolar 7 matérias. Partidos de todos os campos do espectro político também buscam intervir no debate, desde o já mencionado PMDB, que permanece como ator mais presente na discussão, com 10 propostas, até partidos mais à direita (PTR, PRN, PFL) ou à esquerda (PT, PDT, PSB). ${ }^{15}$ Cabe destacar também que, à diferença do momento anterior, nem todas as propostas foram arquivadas, sendo que 4 delas chegaram a virar norma jurídica, nenhuma delas de autoria de deputado federal. Além do PL n. ${ }^{\circ} 4.716 / 94$, de autoria do Poder Executivo, e que se tornaria posteriormente a lei n. ${ }^{0}$ 9.455/97, a Câmara aprovou, por iniciativa da Comissão de Relações Exteriores, a adesão do país a duas convenções internacionais relativas à tortura: Convenção Interamericana para Prevenir e Punir aTortura e a Convenção das Nações Unidas contra a Tortura e outros Tratamentos ou Penas Cruéis, Desumanos ou Degradantes, ambas apresentadas em 1986 e transformadas em decreto legislativo em 1989. A aprovação dos tratados buscava mudar a imagem do Brasil no exterior, saldando o que Gelson Fonseca Jr. (1998) classificou como hipotecas internacionais que a democracia nascente no país precisava resolver.

A outra iniciativa legislativa aprovada na Câmara dos Deputados, entre 1985 e 1996, foi o $\mathrm{PL}$ n. ${ }^{\circ}$ 5.405/90, que posteriormente se transformaria na lei ordinária 8.072/1990, conhecida como lei dos crimes hediondos. A iniciativa, neste caso, veio do Senado Federal, onde o senador Odacir Soares (PFL/RO) propôs o então PLS n. ${ }^{\circ}$ 50/90. A tramitação do texto na Câmara dos Deputados demorou menos de um mês e, pouco depois da aprovação em plenário, o texto foi promulgado pelo presidente da república. Como dito anteriormente, diversos projetos versaram sobre a regulamentação de diferentes incisos do artigo quinto da Constituição de 1988, com preocupação especial na definição dos crimes hediondos. A partir da

\footnotetext{
15 No total, 11 partidos diferentes estiveram envolvidos nas proposições acerca do tema no período 8596: PDC, PTB, PDT, PFL, PMDB, PRN, PSB, PSD, PSDB, PT e PTR.
} 
aprovação desta lei, consolidou-se a equiparação da tortura e outros crimes que podem ser cometidos tanto por agentes privados quanto públicos, como terrorismo, sequestro e tráfico de entorpecentes. Produz-se então um deslocamento em relação à demarcação observada no período anterior, que restringia o debate sobre tortura à proteção dos cidadãos contra o arbítrio de agentes do Estado.

A partir do momento em que os partidos de direita passam a mobilizar o tema da tortura na disputa política, os sentidos das propostas legislativas se abrem, assumindo inclusive conotações "punitivistas" em muitos casos. O deputado Francisco Silva (PDC/RJ) propôs, por meio do PL n. ${ }^{\circ} 1.471 / 91$, que os órgãos de condenados por crimes hediondos fossem compulsoriamente doados, independentemente do desejo de suas famílias ${ }^{16}$. Já Marquinhos Cheidid (PSD/SP) apresentou projeto que isenta de responsabilidade penal aquele que age em situação de "violenta emoção", em decorrência de tortura ou agressão sofrida. Em certa medida, seu PL n. ${ }^{\circ} 319 / 95^{17}$ guarda enorme similaridade com a proposta enviada pelo então ministro da Justiça, Sérgio Moro, no âmbito do chamado Pacote Anticrime, segundo o qual os homicídios cometidos neste estado deveriam estar isentos do processo penal. Os três projetos apresentados pelo PTR no período se dedicam a agravar penas e determinar as condições de cumprimento das mesmas. No caso do PFL, em 4 das 5 propostas o partido se preocupa com a definição dos crimes hediondos, inafiançáveis e imprescritíveis, no mesmo espírito da legislação aprovada em 1990. Em todos os casos, nota-se a equiparação da tortura a outros crimes considerados graves e a abertura para que seja tratada como produto da ação de agentes públicos e privados, especialmente quando se enfatiza seu uso nas situações de sequestro.

Dentre os partidos de esquerda e centro-esquerda, a tendência no período segue sendo a de projetos que se relacionem de alguma maneira com o tema da

\footnotetext{
${ }^{16}$ https://www.camara.leg.br/proposicoesWeb/fichadetramitacao?idProposicao=192548

${ }^{17}$ https://www.camara.leg.br/proposicoesWeb/fichadetramitacao?idProposicao=174976
} 
violência de Estado, especialmente no contexto da última ditadura militar. PDT e PSDB apresentam propostas de anistia aos perseguidos políticos e celebração dos mesmos como heróis nacionais, ao passo que o PT apresenta proposta no sentido de definir crimes contra a Humanidade e o Estado Democrático de Direito ${ }^{18}$. O PMDB, partido que tem o maior número de propostas apresentadas, também mantém as preocupações do período anterior, apresentando matérias acerca do abuso de autoridade, de crimes contra a humanidade e da tortura como pena cruel, versando especificamente sobre réus em custódia do Estado.

\section{LEI $n .^{\circ} 9.455 / 97$}

O projeto de lei n. ${ }^{\circ}$ 4.716/94, que depois se converteria na lei n. ${ }^{\circ}$ 9.455/97, representa um marco em nossa discussão por tratar-se da proposta convertida em norma jurídica mais específica sobre o tema da tortura em todo o período analisado. Apresentada pelo Poder Executivo à Câmara dos Deputados em 30/08/1994, com objetivo de definir o crime de tortura e dar outras providências. A legislação aprovada não sofreu alterações significativas em relação ao texto inicialmente proposto pelo Executivo. Composta de apenas 4 artigos, a matéria delimita o que é tortura, estabelece as penas e os agravantes no julgamento deste crime. Em mensagem anexada pelo então Ministro da Justiça, Alexandre de Paula Dupeyrat Martins, ressalta-se a importância da adequação do ordenamento jurídico brasileiro aos tratados internacionais com os quais se comprometeu no final da década de 1980, bem como com o espírito da Constituição Federal de 1988, razão pela qual recomenda, inclusive, que a presidência requeira regime de

\footnotetext{
${ }^{18}$ Ver os seguintes exemplos:

https://www.camara.leg.br/proposicoesWeb/fichadetramitacao?idProposicao=18156; https://www.camara.leg.br/proposicoesWeb/fichadetramitacao?idProposicao=221462 e https://www.camara.leg.br/proposicoesWeb/fichadetramitacao?idProposicao=228736
} 
urgência na tramitação..$^{19}$ Este recurso de fato foi utilizado pelo Poder Executivo, em maio de 1996, o que acelerou significativamente a apreciação da matéria, aprovada em plenário em 03/07/1996.

Antes disso, a matéria já tivera sua constitucionalidade aprovada pela Comissão de Constituição, Justiça e Cidadania (CCJC), quando o presidente da Comissão de Direitos Humanos $(\mathrm{CDH})$ requisitou à mesa diretora da Câmara que o texto passasse também por aquela instância. Foi nesse momento em que, por ação dos deputados Pedro Wilson (PT-GO) e Hélio Bicudo (PT-SP) houve alguma pressão em torno do alargamento da compreensão do problema da tortura, acentuando sua relação com as autoridades públicas e o legado do regime militar. Assim, Wilson, relator na $\mathrm{CDH}$, justificou a apresentação de substitutivo lembrando que oito projetos haviam sido apresentados no legislativo em relação ao tema da tortura. Dentre estes, constava um texto que versava sobre os crimes contra o Estado democrático e a humanidade e a Lei de Segurança Nacional (PL n. ${ }^{\circ}$ 4.783/90) e outro projeto de substituição integral da Lei de Segurança Nacional (PL n. ${ }^{\circ}$ 2.462/91). Os dois tratavam de temas mais abrangentes, como o genocídio, crimes contra a humanidade, terrorismo e desaparecimento de pessoas. Os demais seis circunscreviam suas propostas de maneira mais específica à questão da delimitação e penas para o crime de tortura. A movimentação dos deputados na $\mathrm{CDH}$ resultou em solicitação para apensar o $\mathrm{PL}$ n. ${ }^{\circ}$ 4.783/90 ao processo de tramitação do PL n. ${ }^{\circ}$ 4.716/94, o que foi aprovado pela Mesa Diretora em 1995.

No ano seguinte, em sequência ao requerimento de urgência enviado pelo Poder Executivo, a Mesa Diretora da Câmara atendeu a um ofício da Comissão de Constituição e Justiça solicitando que os projetos fossem novamente separados, o que resultou no desapensamento do $\mathrm{PL}$ n. ${ }^{\circ}$ 4.783/90. A argumentação apresentada pelo deputado Ibrahim Abi Ackel (PP-SP) sustentava que a apreciação dos dois

\footnotetext{
${ }^{19}$ Ver mensagem do ministro da Justiça disponível no dossiê completo da matéria no acervo da Câmara dos Deputados:

https://www.camara.leg.br/proposicoesWeb/prop_mostrarintegra;jsessionid=nodeOfikraq7nnb3g4 g6v6at14ia9690807.node0?codteor=1136696\&filename=Dossie+-PL+4716/1994
} 
projetos aumentaria demais o escopo da discussão, o que poderia trazer resistências que retardariam a aprovação da matéria. Embora pareçam tecnicalidades do processo de apreciação de uma matéria no poder legislativo, estas manobras representam a linguagem pela qual se materializaram disputas em torno da definição do problema da tortura no país. É fundamental lembrar, para compreender a disputa em questão, que o deputado Abi Ackel fora ministro da Justiça do último governo militar, filiado durante muito tempo ao partido do regime, a ARENA, e, posteriormente às agremiações que a sucederam, como o PDS, o PPR e, finalmente, o PP.

O que estes pequenos requerimentos, solicitações e atos administrativos traduzem, portanto, é a tensão entre atores políticos que conferem maior ou menor centralidade à relação entre o problema da tortura e o autoritarismo da última ditadura. Enquanto para os deputados da CDH era necessário ampliar a discussão para tocar em pontos nevrálgicos do funcionamento da repressão do regime anterior, para parlamentares como Abi Ackel, comprometidos com a ordem anterior, a matéria da tortura deveria ser tratada em termos mais abstratos e desvinculados de um debate sobre sua história e suas manifestações concretas na formação brasileira. Não deixa de ser curioso que a via para este enfrentamento tenha escapado do confronto aberto de ideias, apoiando-se no expediente de afastar temas polêmicos para avançar consensos minimalistas em maior velocidade. São termos compatíveis com um momento no qual os herdeiros do regime anterior atuam de maneira "envergonhada" (Quadros e Madeira, 2018).

As poucas manifestações de objeção ao texto do PL n. 4.716/94 partem de figuras menos centrais no jogo político de então, até certo ponto caricatas. Foi o caso dos dois inscritos para falar contra o projeto na sessão plenária que o aprovou, os deputados Agnaldo Timóteo e Arnaldo Faria de Sá. Também vale lembrar a apresentação de destaque pelo então deputado Jair Bolsonaro, que desejava 
retirar do texto as expressões grave ameaça e menta ${ }^{20}$ constantes no primeiro artigo do texto em discussão. Sua proposta foi derrotada em votação, com 272 votos contrários e 83 favoráveis. A ação do deputado revela preocupação em reduzir ao mínimo possível a delimitação do que configura prática de tortura, aumentando a discricionariedade disponível à autoridade que conduz interrogatório. Nota-se aqui linha de continuidade direta com as pautas defendidas até hoje, sempre em defesa de menores constrangimentos legais para a atuação de quem está na "linha de frente". ${ }^{21}$

Entretanto, por mais que estas manifestações nos ajudem a traçar linhas de continuidade entre o passado e as posições mais recentes de questionamento dos direitos humanos como conjunto de princípios e marcos normativos, naquele momento a oposição ao projeto enviado pelo governo foi pouco significativa. Embora os setores mais à esquerda da Câmara tenham sido derrotados em seu intuito de ampliar o escopo da discussão para outras estruturas legadas do regime anterior, o texto sobre tortura foi aprovado em redação muito próxima à original, com pequenas alterações de forma.

\section{PERÍODO 1997-2021}

Diante da impossibilidade, no escopo desse artigo, de abordar sistematicamente um conjunto tão vasto de mais de 500 propostas que foram identificadas a partir do termo "tortura", optamos por delimitar a análise em torno dos 37 projetos que propõem alterações na lei n. 9.455. Não obstante a apresentação dessas 37 propostas, desde 1997, a lei contra a tortura só teve, até

\footnotetext{
20 Diz a redação do artigo 1 da lei: "I - constranger alguém com emprego de violência ou grave ameaça, causando-Ihe sofrimento físico ou mental".

${ }^{21}$ Ver por exemplo https://oglobo.globo.com/brasil/bolsonaro-deve-enviar-ao-congresso-projetopara-dar-retaguarda-juridica-militares-policiais-em-servico-23755039
} 
2021, uma pequena retificação. $O$ inciso II do $\S 4^{\circ}$ passou a ter a seguinte redação: "Il - se o crime é cometido contra criança, gestante, portador de deficiência, adolescente ou maior de 60 (sessenta) anos". A alteração se deu em decorrência da aprovação da lei n. 10.741 de 2003 (Estatuto do Idoso). ${ }^{22}$

Em relação à filiação partidária dos deputados que apresentaram propostas de mudança na lei n. 9.455, a análise das 37 propostas mostra que os partidos mais atuantes foram o PT (7), PMDB/MDB (6), PSDB (4), PPS (3) e PFL/DEM (4), perfazendo um total de 22, ou seja, 65\%. As demais propostas se dispersaram por outros 10 partidos (PSB, PPB, PTB, PP, PDT, PRB, PC do B, REDE, PSL, PODE). E houve, ainda, uma proposta apresentada pelo Senado em decorrência de uma Comissão Parlamentar Mista de Inquérito relativa à Violência contra a Mulher.

Nos dez primeiros anos de vigência da lei, ou seja, entre 1997 e 2006, foram apresentadas 21 propostas de alteração da lei (56,7\%). As demais 16 (43,3\%) ocorreram entre 2008 e 2021. Optou-se por fazer uma agregação dos projetos de lei a partir de tom predominante de seu conteúdo mesmo considerando que alguns projetos combinavam diferentes elementos (diversificação das vítimas, aumento de pena, regime de cumprimento de pena) mas que aqui foram separados para fins de análise.

Assim, em relação ao conteúdo dos projetos de lei, 19 deles (51\%) tinham como alvo principal o agravamento das penas previstas na lei, considerando leves as penas em comparação com outros crimes ou mesmo face à gravidade do delito e da vulnerabilidade das vítimas. Dentre estes 19 projetos, alguns eram voltados especificamente para o $\S 7^{\circ}$ da lei que dispunha que "O condenado por crime previsto nesta Lei, salvo a hipótese do $\S 2^{\circ}$, iniciará o cumprimento da pena em regime fechado". Ou seja, indicava a possibilidade de progressão no regime de cumprimento da pena de reclusão. Alguns deputados apresentaram propostas de retirar a possibilidade de progressão, uma vez que alegavam que juízes, amparados

\footnotetext{
$22 \mathrm{Na}$ redação anterior constava apenas "II - se o crime é cometido contra criança, gestante, deficiente e adolescente".
} 
no texto da lei contra a tortura, estavam concedendo esse benefício a condenados enquadrados na chamada lei dos Crimes Hediondos (lei n. 8.072/90) que vetava esse benefício ${ }^{23}$.

A partir de 2003, surgem oito propostas de mudança na lei (21,6\%) destinadas a explicitar a discriminação por sexo ou gênero (na letra c do inciso do art. $1^{\circ}$ ) e, mais especificamente, para tipificar e punir a violência doméstica e contra a mulher. Cinco das oito propostas foram apresentadas por deputadas, duas por deputados e outra foi apresentada a partir do PLS n. 293 do Senado, em decorrência da Comissão Parlamentar Mista de Inquérito sobre a Violência contra a Mulher (2012).

Verifica-se que apenas cinco propostas (13,5\%) estavam destinadas diretamente a fazer mudanças no sentido de alinhar a lei aos instrumentos internacionais de prevenção e de combate ao crime da tortura. Todos foram apresentados por deputados do PT. Dois deles foram claramente voltados para a criação de meios diversos de divulgação da lei, de educação nos ambientes escolares e, portanto, criando mecanismos de prevenção.

Os projetos de lei, na sua maioria, não colocaram como questão central mecanismos ou procedimentos destinados à responsabilização do agente público que pratica a tortura. No entanto, esse problema foi apresentado em quatro projetos, todos destinados a tornar ainda mais difícil a responsabilização dos policiais envolvidos com a tortura. Representam os quatro projetos de lei 10,8\% de todas as propostas e foram apresentados por deputados oriundos das polícias militares. Três deles buscavam evitar a perda do cargo público em decorrência de condenação de agente por prática de tortura como estava previsto na lei (" $\S 5^{\circ} \mathrm{A}$ condenação acarretará a perda do cargo, função ou emprego público e a interdição para seu exercício pelo dobro do prazo da pena aplicada"). Propunha-se que a perda do cargo só poderia ocorrer depois de instalado procedimento

\footnotetext{
23 Depois de muitas polêmicas sobre a constitucionalidade da vedação da progressão de regime na lei n. 8.072/90, a lei n. ${ }^{\circ} 11.464$ restituiu a possibilidade desse benefício, alterando a chamada lei dos crimes hediondos $\left(\S 7^{\circ}\right.$ do art. $\left.2^{\circ}\right)$.
} 
administrativo que avaliasse a procedência ou não dessa perda, mesmo depois do agente ter sido condenado judicialmente por crime de tortura.

Por fim, um dos quatro projetos buscava retirar os interrogatórios policiais dos cenários possíveis da prática da tortura. Propunha a inclusão de um novo parágrafo ao artigo $1^{\circ}$ da lei nos seguintes termos: "§ $8^{\circ}$ Não constitui crime de tortura psicológica o interrogatório policial e demais questionamentos dos Agentes de Segurança Pública, que visem esclarecimentos dos fatos".

\section{CONSIDERAÇÕES FINAIS}

Ao longo do texto, buscamos recuperar a maneira pela qual deputados federais em diferentes momentos históricos tomaram o tema da tortura como eixo de sua atividade legislativa. Para tanto, levantamos e analisamos as propostas apresentadas por parlamentares do fim dos anos 1960 até o presente. Identificamos importantes inflexões no tratamento deste problema no longo período analisado. Percebemos que, durante a última ditadura militar (1964-1985), as poucas propostas apresentadas tinham como preocupação central o arbítrio de agentes do Estado no exercício de suas funções, sempre levando em consideração o contexto de repressão sobre dissidentes políticos do regime. A tortura, naquele momento, é entendida não apenas como um problema de direitos civis, mas também como uma questão sensível para a garantia dos direitos políticos. Após a promulgação da Constituição de 1988, importante marco da transição para a democracia, a discussão sobre o tema passa a ser atravessada pela necessidade de regulamentação de dispositivos constitucionais.

Nesse sentido, amplia-se o número de propostas legislativas, bem como aumenta a variedade de temas correlatos que aparecem quando se fala sobre tortura. Se, no regime anterior, as propostas foram todas formuladas por opositores à esquerda do governo, a partir do final da década de 1980 há maior pluralidade nos atores que propõem leis relativas à tortura, muitos deles falando sobre crimes 
hediondos e instrumentos punitivos. Nesse momento, já não conseguimos observar um padrão claro e coerente das propostas apresentadas por parlamentares sobre o problema. Essa diversidade de vozes que começam a falar sobre tortura no Congresso Nacional aparece de maneira mais clara no processo de tramitação da Lei n. ${ }^{\circ}$ 9455/97, quando houve significativa movimentação de setores políticos opostos entre si para disputar o sentido da nova legislação. Enquanto políticos mais à esquerda buscaram associar o tema às heranças autoritárias e a questões como a Lei de Segurança Nacional e os Crimes contra a Humanidade, representantes à direita do espectro político - quando não se opuseram à lei - ressaltaram a importância de aprovar o texto de acordo com consensos mínimos e abstratos, sem colocar o tema da tortura em perspectiva histórica.

Dali em diante, diversas foram as propostas legislativas, muitas delas dedicadas a alterar aspectos da lei sancionada em 1997. Observamos que a diversificação notada no período anterior aumentou significativamente e, embora os partidos mais à esquerda sigam apresentando o maior número de propostas, há importante produção por parte dos atores mais à direita do sistema político. Nesse sentido, cabe notar também que o teor das discussões já não se resume à necessidade de proteção dos indivíduos contra a tortura, mas muitas vezes se concentra no incremento de instrumentos punitivos disponíveis às autoridades do Estado. Ressaltamos também que mesmo com crescimento expressivo do número de propostas de alteração legislativa, praticamente não há menção à mecanismos de prevenção ou políticas públicas que não passem pela punição dos que já cometeram o crime.

O tema da tortura pode ser compreendido como uma janela para longas discussões acerca do processo de formação da sociedade e do Estado no Brasil, assim como da atualização de diversos meios de punição historicamente empregados no país - seja por agentes públicos ou privados. Presente como prática social desde os primeiros momentos da colonização, o emprego de castigos corporais e de expedientes diversos de pressão psicológica e dissolução de laços 
familiares e sociais antecede a própria classificação destes mecanismos como tortura. O longo caminho do pelourinho ao pau-de-arara inclui uma enorme variedade de práticas que, em diferentes momentos, foram inventariadas por atores e autores. Estes inventários de sujeitos e práticas que constituem o mundo da punição no Brasil, bem como suas relações, causas e motores de ação, constituem tema fundamental para o funcionamento de toda a sociedade.

Por meio deste levantamento de propostas legislativas, acrescentamos uma dimensão que nos parece relevante para a compreensão do problema. Não apenas nos dedicamos a um ator menos presente nestas discussões - o representante, legislador - como ressaltamos um momento importante dos processos punitivos, aquele em que se busca traduzir um conjunto de práticas como problema político, disputando os enquadramentos em determinadas lentes e prevendo, por consequência, certos caminhos de ação política para o enfrentamento da questão. O que olhamos, portanto, foram os expedientes que tornaram complexas as discussões acerca da tortura, disputando sua definição e, principalmente, suas formas de enfrentamento - muitas delas reafirmando o lugar da punição como central na resolução dos conflitos sociais. Tais disputas permanecem em aberto e requerem constante monitoramento, de maneira que possamos identificar as posições em debate e os circuitos que incentivam ou interrompem a atualização de práticas sociais específicas.

\section{REFERÊNCIAS}

Alvarez, M. C. (2008). Tortura, História e Sociedade: algumas reflexões. Revista Brasileira de Ciências Criminais, v. 16, 275-294.

Arquidiocese de São Paulo. (1985). Brasil nunca mais. $3^{a}$ ed. Petrópolis: Vozes. 
Calderoni, V., \& Jesus, M. G. M. de. (2015). Julgando a tortura: análise de jurisprudência nos tribunais de justiça do Brasil (2005-2010). São Paulo: ACAT-Brasil/Conectas/NEV-USP/IBCCRIM/ Pastoral Carcerária.

Fortes, L. R. S. (2012). Retrato calado. São Paulo: Cosac Naify.

Godoi, R. (2019). A prisão fora e acima da lei. Tempo Social [online]. v. 31, n. 3, 141-160. https://doi.org/10.11606/0103-2070.ts.2019.161053

Gomes, M. de S. (2017). Isso é tortura? Disputas, consensos e narrativas na construção social do crime de tortura na cidade de São Paulo. Dissertação de Mestrado em Ciências Humanas e Sociais. Universidade Federal do ABC. São Bernardo do Campo.

Huggins, M. K. (2006). Operários da violência. Brasília: Editora da Universidade de Brasília.

Jesus, M. G. M. de. (2010). O Crime de Tortura e a Justiça Criminal: um estudo dos processos de tortura na cidade de São Paulo. São Paulo: IBCCRIM, vol. 55.

Mendiola, I. (202) En torno a la definición de tortura. Dados, Rio de Janeiro, vol. 63 (2), 1-32.

NEV - Núcleo de Estudos Da Violência (2012). $5^{\circ}$ Relatório Nacional sobre os Direitos Humanos no Brasil, 2001-2010. São Paulo: NEV-USP/Fapesp/Urbania.

Ocariz, M. C. (org.). (2015). Violência de Estado na ditadura civil-militar brasileira (1964-1985): efeitos psíquicos e testemunhos clínicos. São Paulo: Escuta.

Pastoral Carcerária. (2016). Tortura em tempos de encarceramento em massa. São Paulo: Pastoral Carcerária. 
Pastoral Carcerária. (2018). Tortura em tempos de encarceramento em massa. Pastoral Carcerária Nacional - CNBB.

Pires, A. (2004). A racionalidade penal moderna, o público e os direitos humanos. Novos Estudos Cebrap, 68, 39-60.

Possas, M. T. (2015). Produção de leis criminais e racionalidade penal moderna: uma análise da distinção 'conservador' x 'progressista' no caso da criação da lei contra a tortura no Brasil. Dilemas. Revista de Estudos de Conflito e Controle Social, 8(3), 473-499.

Possas, M. T. (2016). A Lei Contra a Tortura no Brasil, a construção do conceito de "crime de lesa-humanidade" e os paradoxos da punição crimina. Revista de Estudos Empíricos em Direito, 3(1), 98-112.

Quadros, M. P. dos R., \& Madeira, R. M. (2018). Fim da direita envergonhada? Atuação da bancada evangélica e da bancada da bala e os caminhos da representação do conservadorismo no Brasil. Opinião Pública, 24 (3), 486522.

Reis, D. A. (2010). Ditadura, Anistia e Reconciliação. Estudos Históricos, Rio de Janeiro, v. 23, n. 45, 171-186. https://doi.org/10.1590/S0103-21862010000100008

Salla, F., \& Alvarez, M. C. (2006). Apontamentos para uma história das práticas da tortura no Brasil. Revista Brasileira de Ciências Criminais, 63, 277-308.

Salla, F., Jesus, J., \& Jesus, M. G. M. (2016). Investigação e processamento de crimes de tortura em Goiânia, Curitiba e Belo Horizonte. In: Pareschi, A. C. C., Engel, C. L., \& Baptista, G. C. (orgs.). Direitos humanos, grupos vulneráveis e segurança pública. 1. ed. Brasília: SENASP, Ministério da Justiça, v. 6, 111-148. 
Sussman, David. (2005) What's wrong with torture? Philosophy and Public Affairs, vol.33, $n^{\circ} 1,1-33$

Vargas, J. D. (2012). Em busca da "verdade real": tortura e confissão no Brasil ontem e hoje. Sociologia \& Antropologia [online]. v. 2, n. 3, 237-265. https://doi.org/10.1590/2238-38752012v2310

'Pedro Benetti: cientista político, professor da UERJ e pesquisador do Núcleo de Estudos da Violência da USP (NEV-USP). Email: pedro.benetti@uerj.br.

iiFernando Salla: sociólogo, pesquisador do NEV-USP. Email: fersalla@gmail.com.

iiiMarcos César Alvarez: sociólogo, professor da USP e coordenador do NEV-USP. Email: mcalvarez@usp.br.

Data de submissão: 08/02/2021

Data de aprovação: 15/05/2021 